\title{
Online or conventional democracy? The Ashgrove election and networked journalism
}

\begin{abstract}
This study focuses on new media use in democratic discourse, specifically in the Queensland state electoral division of Ashgrove in 2011. This site was chosen to make an enquiry into the place of mass media in public decisionmaking, asking the question: did online media provide an extension of democracy, and what would be journalism's role in democratic discourse? The study utilises a survey of 280 constituents, a review of pertinent news coverage, and extensive interviews with a panel of informants. In the outcome, it found those most equipped to utilise online media showed a lack of will to get involved in deeper political, social engagements. It also sees younger demographics forming news habits, not usually in step with traditional political avenues, based on familiarity with online processes, while consciously marginalising the need for trustworthiness in this setting. These issues are considered together with one leading proposal as to where the future of new media might be heading. It assesses the notion of professional and amateur collaboration by employing the model articulated by Beckett, called 'networked journalism'.
\end{abstract}

Keywords: Ashgrove, digital journalism, networked journalism, new media, public sphere

STEVE FOX and LEE DUFFIELD

Queensland University of Technology

TN THE past decade, the nature of media and who creates it has changed with the proliferation of digital media (Atton \& Hamilton, 2008; Beckett \& Ball, 2012; McChesney \& Pickard, 2011). These complex developments have raised a vast array of issues concerning journalism's role in democratic society (Beckett, 2008; Habermas, 2006). It has left researchers

176 PACIFIC JOURNALISM REVIEW 19 (2) 2013 
with the task of investigating, evaluating and proposing how 'new' media may develop in the near future, as the notions of what constitutes a healthy, civic society become of growing concern in the digital age (Richards, 2007).

This article pursues this discussion, and focuses on new media in the Queensland state electoral division of Ashgrove early in 2011. In the lead-up to the Queensland state elections of 2012, considerable media attention and public interest was focused on the ultimately successful bid by the Liberal National Party leader, Campbell Newman, to become premier by winning the elections generally; but also by himself defeating a Labor Minister, and sitting member for Ashgrove, Kate Jones. This was chosen as the site to make an inquiry into the place of mass media in public decision-making, in particular new media. The question was asked: In the case of the Ashgrove election campaign, did online media provide an extension of democracy, and what would be journalism's role in democratic discourse? This article will then attempt to assess one leading proposal as to where the use of new media might be heading, the notion of a professional and amateur collaboration, employing the model articulated by Beckett (2008), called 'networked journalism'.

In the outcome, the research (which included a survey on voting intentions) anticipated the result of the election that came to be held on 24 March 2012, and then set out to examine possible links between voters' decision-making, and their use of media. It has established that voters say they use media as a principal tool for their decision-making, with mainstream, so-call 'old' media most often mentioned. At the same time, the study finds that general levels of political awareness, faith in the importance of politics in settling social issues, and political participation are rather weak in the Ashgrove electorate. That is less so in the case of older voters, opening up an age divide, with these voters much more inclined to follow mainstream media. The lack of awareness or political consciousness is pronounced among younger electors who make up, also, by far the principal group of users of new media. However, while it may be little used for political communication to date, this study finds new media to be heavily used by the many people exposed to it - so its potential in political discourse has to be noted.

\section{Literature review: New media and the public sphere}

Prior to the proliferation of the online medium, the business of news production belonged primarily to journalists, in what is known as the 'old' media 
model (Gillmor, 2004, p. 12; Overholser, 2006, p. 20; Viall, 2009, p. 14). A significant characteristic of this model was the distinct divide between the audience and media, arguably the source of its greatest strength and weakness (Beckett, 2008, p. 62). Old media's approach to journalism was to instil objectivity by separating the producer from the public - an idea represented in theories such as Walter Lippmann's (1997) basic transmission model, which limited public involvement in the news process (p. 145). Lippmann was known for propounding liberal thought, and his theories were justifiable in situations where the number of media channels was limited, with space and airtime strictly rationed (Blumenthal, 2007). However, the digital age has rather out-dated such theories, enabling, as Gillmor (2004) describes it, 'a medium for everyone's voice, not just the few who can afford to buy multimillion-dollar presses' (p. 13). Likewise, this new form of publishing has presented fresh opportunities for journalism as well, giving rise to new media models.

The distinguishing feature of new media is the digitisation of media content. This process offers a more participatory form of journalism online, through social networking sites, blogs and wikis, creating an environment where collaborative efforts are further facilitated (Gillmor, 2004, p. 45; Meikle \& Redden, 2011; Pavlik, 2001, p. 19). Though intimately linked to old media, it is a development providing competition to the dominant, commercial news media and 'draining resources from traditional journalism' (Meikle \& Redden, 2011, p. 55). In fact, financial dynamics are often blamed for the degradation of news values already evident in an increasingly commercialised industry (Franklin, 2012; Henry, 2007, p. 65). Discourses about the changes taking place can foster polarised views of the new media debate: On one side of the spectrum lie internet advocates, such as Gillmor (2004), who welcome the idea that new media will bring down old media's gates, and on the other side are those such as the United States Federal Communications Commission chairman, Kevin Martin, who believe active steps should be taken to preserve the traditional estate of journalism as it exists (Federal Communication Commission Oversight Hearing, 2007).

To further understand how far these elements matter for journalism in society, political philosopher Jurgen Habermas's work, specifically his public sphere theory, serves as a useful framework. Habermas's first major book, The Structural Transformation of the Public Sphere (1991), proposed

178 PACIFIC JOURNALISM REVIEW 19 (2) 2013 
the theoretical concept of the public sphere as a space in which the public body could engage in critical debate, with the purpose of regulating civil society (p. 52). Habermas argues this ideal public sphere was lost when the media became an overwhelmingly-commercial interest during the 20th century (Habermas, 1991, p. 50; Habermas, Lennox \& Lennox, 1974, p. 53). This deterioration of the function of the public sphere is exacerbated by structural transformations caused by new technology, and consequent social shifts - a major symptom being a fragmentation of audiences (Kushin, 2010, p. 153; Tewksbury, 2005, p. 332). As available settings for debate in a public sphere will change, so must journalism change, and as Beckett (2008) proposes, his notion of networked journalism, is the 'inevitable, or certainly the most desirable, response to this changing dynamic' (p. 34).

\section{A networked journalism approach to new media challenges}

The term networked journalism is a theoretical proposition derived from the collaborative aspect of current journalistic practice; notably it anticipates the future scope for interactivity within digital media. The theory focuses on the production of news through a potential network that utilises public engagement, as proposed by Jarvis (2006) and later articulated by Beckett (2008). Members of a general public are able to contribute to the news process through the stages of inception, reporting and review. A defining feature of networked journalism would be involvement of professional journalists to participate, often as moderators, in a way that will make each operation cohere. It would have to be assumed there will be enough social infrastructure to provide for this informed contribution - answering a concern of theorists most interested in the potential threats of fragmenting audiences online (Pavlik, 2001, p. 28; Richards, 2007).

Inherent in the internet's democratisation of the media is choice for audiences. This choice can also be described as fragmentation, or separation, of these audiences (Beckett, 2008, p. 24; Sonnenberg, 2009, p. 8). This raises concerns voiced by Ed Richards (2007), chief executive of Ofcom, the organisation that regulates British Broadcasting, regarding users 'getting specific information about single issues that interest them as consumers rather than following news more widely as citizens'.

Habermas (2006) shares a similar apprehension of the internet, arguing that with the 'decentralised access to unedited stories ... contributions by 
intellectuals lose their power to create a focus'. This collective loss of quality exchange can contribute to an environment where the social discourse lacks enough focus to unite, and see discussed, concepts in the public sphere realm. Beckett (2008) explains networked journalism can possibly address these issues by sharing the news process with the public, cultivating a relationship of 'greater transparency and responsibility' (p. 62). That may have the potential to revitalise the fourth estate, addressing concerns Schudson (2002) presented, regarding the exclusivity of the public domain to "elites", and media's role in perpetuating that elitist tendency (p. 156).

However, while the theory supporting this premise may be persuasive, it assumes a certain level of social infrastructure with which to support processes of public consumption, understanding and utilisation of new media; in particular, the proficiency of digital tool use among the population, and willingness to engage in deeper, social interactions. Currently, research into this field of professional-amateur operations (embodied here as the networked journalism model proposed by Beckett), is rather new. It is posited here that an important element in this emerging field of research may be to identify the foundations of social processes and audiences upon which collaborative, new media models are being built.

\section{Methodology: Case study selection}

In response to the concerns outlined in the literature, the authors used the contest between Campbell Newman of the Liberal National Party (LNP), and Kate Jones of the Australian Labor Party (ALP), for the Queensland state electoral division of Ashgrove during 2011, as a case study. A case study approach was chosen here as it lends itself to the investigation of phenomena that are highly contextualised, requiring multiple methods of enquiry such as the study of online media networks and social media (Yin, 1984, p. 23).

The contest for the Ashgrove electorate provides an opportunity to test theoretical notions of the appropriateness, or usefulness, of new media in making public discourse. First, the high-profile nature of the candidates invited a concentration of media activity, affording the opportunity to study the use of media by constituents to develop voting intentions. Second, it embodied a political issue that had some immediate consequence (with the election, already predicted at the time, to take place early 2012), of the very question of who governs.

180 PACIFIC JOURNALISM REVIEW 19 (2) 2013 


\section{Methods: Research design}

This research employs mixed methods, though the overall strategy favours a qualitative approach. As articulated by Mason (2002), it becomes necessary to think in qualitative ways when approaching a research design, where several variables are in play, because 'qualitative research is characteristically exploratory, fluid and flexible, data-driven and context-sensitive' (p. 24). The paper matches material from four sources, listed below, to further substantiate the conclusions made here. A review of literature relevant to the topic:

- A review of literature relevant to the topic;

- A street survey conducted with constituents in the Ashgrove electorate, with the primary purpose to collect data on news consumption, political knowledge, the importance placed on politics by respondents, and voting behaviour and influences;

- A broad review of media content available to constituents, which is considered together with the street survey, informing it, and;

- A schedule of interviews with authoritative informants, asking them to comment on and evaluate the topics and findings of the survey.

\section{Ashgrove survey}

A social survey was utilised as a means to collect primary data on the case study. The survey questionnaire had both a descriptive and explanatory nature, providing 'a way of studying social conditions' and a means to explain the relationships between variables to "test some hypotheses suggested by sociological theory" (Moser \& Kalton, 1971, p. 2). The questionnaire was deployed using a street survey in the electorate during July 2011, with the aim of capturing approximately 1 percent of the voting population, totalling 280 cases. The authors acknowledge the limitations of surveys, where a small sample size (such as one percent) increases the chances of sampling error (Biemer \& Lyberg, 2003, p. 34). For this study, the confidence level is 90 percent and the margin of error is 5 percent. This statistical data can be used as a basis for inductive reasoning, when matched with the interview and news review data collected (Bromley \& Neal, 2011, p. 59; Feeney \& Heit, 2007).

\section{News review}

The news review was conducted from September 12, 2011 to September 23, 2011 inclusive. The media outlets reviewed were chosen based on comments tabulated from the Ashgrove survey, in which respondents named the 
sources of news and information they used most, and included:

- Channel Ten's 5pm hour-and-a-half television news bulletin,

- The Australian Broadcasting Corporation's (ABC) 7pm half-hour television news bulletin,

- The $\mathrm{ABC}$ radio programme $\mathrm{PM}$, aired at $5.10 \mathrm{pm}$ on Radio National for one hour,

- The News Limited-owned newspaper, Courier Mail, daily edition, printed in tabloid format; and,

- The Fairfax-owned Brisbane Times, a South-East Queensland digital-only news site.

The criteria set for the news review were designed to provide an insight into what content, applicable to voting, was available to electors, and to provide information useful to analysis on the issue of audience fragmentation. It did not extend to examining the editorial motivations of the constructs of such media packaging, such as studies conducted by Hess (1996).

\section{Interview method}

Six extensive, in-depth interviews were then conducted during September 2011. The aim of this process was to obtain unique viewpoints and perspectives from informants closely involved in, or well informed on the case under study. They were invited to discuss the political landscape of Ashgrove, suggesting what issues the public will decide the election on, and how the public might be informing themselves about these issues. The six informants were: Kate Jones (Labor State Member for Ashgrove), Tony Gleeson (Ashgrove campaign manager for the Liberal National Party), Manfred Cross (former federal Labor politician and resident of the Ashgrove electorate), Sharon Polkowski (former Liberal campaign manager), Doug Yuille (director of reef policy in the Department of Natural Resources and Environment, former Greens candidate, and resident of the Ashgrove electorate), and Professor Scott Prasser (noted political scientist and resident of the Ashgrove electorate).

The semi-structured interview framework employed allowed the interviewee to comment on four broad subject areas, principally, the Ashgrove political landscape, political decision-making, political participation and communication, and the public sphere present online.

\section{Results: News review analysis}

The choice of main media outlets for this part of the study is consistent with 182 PACIFIC JOURNALISM REVIEW 19 (2) 2013 
what survey respondents said they were most aware of. As will be shown, more habitual users of 'new' online media are hardly engaging with it, to any significant extent, to obtain political information. The findings of this news review are described in terms of the frequency, as well as the content of news about the Ashgrove electoral contest.

The Courier Mail newspaper provided the most frequent coverage of Ashgrove politics, with a total of 18 stories during the period of the study, featuring either or both Campbell Newman and Kate Jones. Second was the Brisbane Times, featuring 10 stories; third was Channel 10 with seven stories; fourth was the $\mathrm{ABC}$ television news with four, and last was the PM radio programme with no stories featuring the candidates.

On average across the outlets, Campbell Newman was mentioned approximately seven times more frequently than Kate Jones. In addition, the content of stories did not vary significantly between the outlets. The television news stations often used the same footage, and had the same angles. The Courier Mail provided the most content, due to the tendency to have stories running over the course of the working week. Stories across all outlets predominatly had a general state-politics angle, and as such neither Kate Jones nor Ashgrove became the focus of many of the news stories noted.

The news review suggests that the content of stories and quality of professional journalism of the media outlets under observation does not vary considerably between them. This might alleviate the concern that the fragmentation of audiences between different mediums and outlets, notably online, has an adverse affect on the notions of an informed citizenry, and on the focus and quality of discussion in the public sphere. However, the survey undertaken in this study suggests these concerns are not entirely imagined.

\section{Survey analysis: Trends in news consumption}

The profile of the survey population details a sample that is appropriate for the purposes of the present study, notably providing information on age and occupational identity (gender breakdown of the survey population was 54 percent males and 46 percent females). This survey group shows similar voting intentions to the larger survey samples taken at the time by polling firms such as ReachTEL. It also has a large percentage of 18 to 35 year-olds (47.9 percent), which is typically desirable when examining digital communication trends, as will be discussed later. Finally, the Statistical Package for 


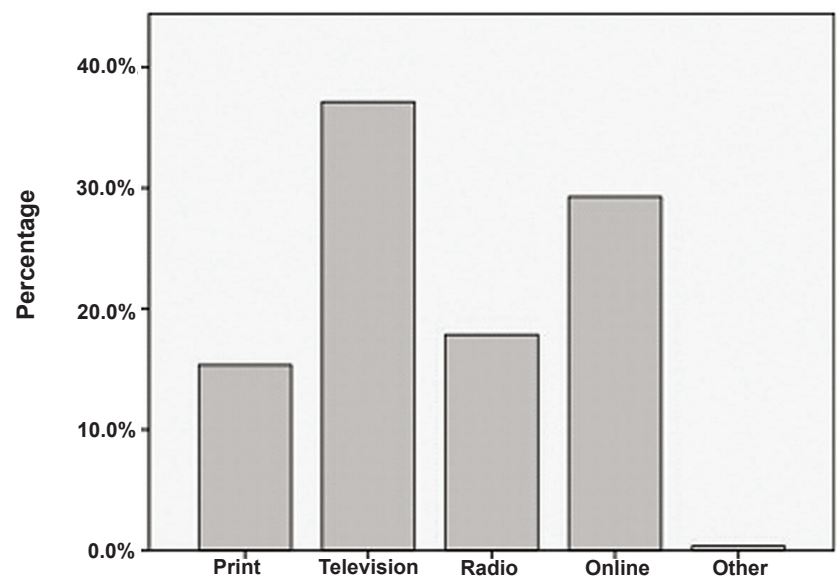

Note: Respondents were asked through which media they received most of their news regarding politics specific to the Ashgrove electorate. The results are expressed as population percentages $(n=280)$.

the Social Sciences (SPSS version 18) used in the collation of this data allows for variable parameters to be set, so that certain age groups can be isolated for analysis.

Results indicate that the majority of the survey population receive most of their news from television outlets (almost 40 percent as shown in Graph 1). However, new media appears to be an emerging trend for news consumption, being the second-most-used medium with just under 30 percent of the survey population using online media most (See Graph 1). While younger voters represent the highest uptake of online media (See Graph 2), the primary reason for using any medium most remains that it is easy to consume and/or access (See Graph 3). From this research, it seems clear that predisposition to what is considered by respondents as easy to consume and/or access, has an influence on what media outlets are used regularly. It is possible to infer then, that younger demographic groupings are forming news habits based on processes that are already familiar, such as online communications and technologies, while consciously marginalising the need for trustworthiness in this setting (See Graph 3 for reasons to consume online media).

In support of the previous inference, further analysis of new media usage shows that there is an inverse relationship between new media usage

184 PACIFIC JOURNALISM REVIEW 19 (2) 2013 


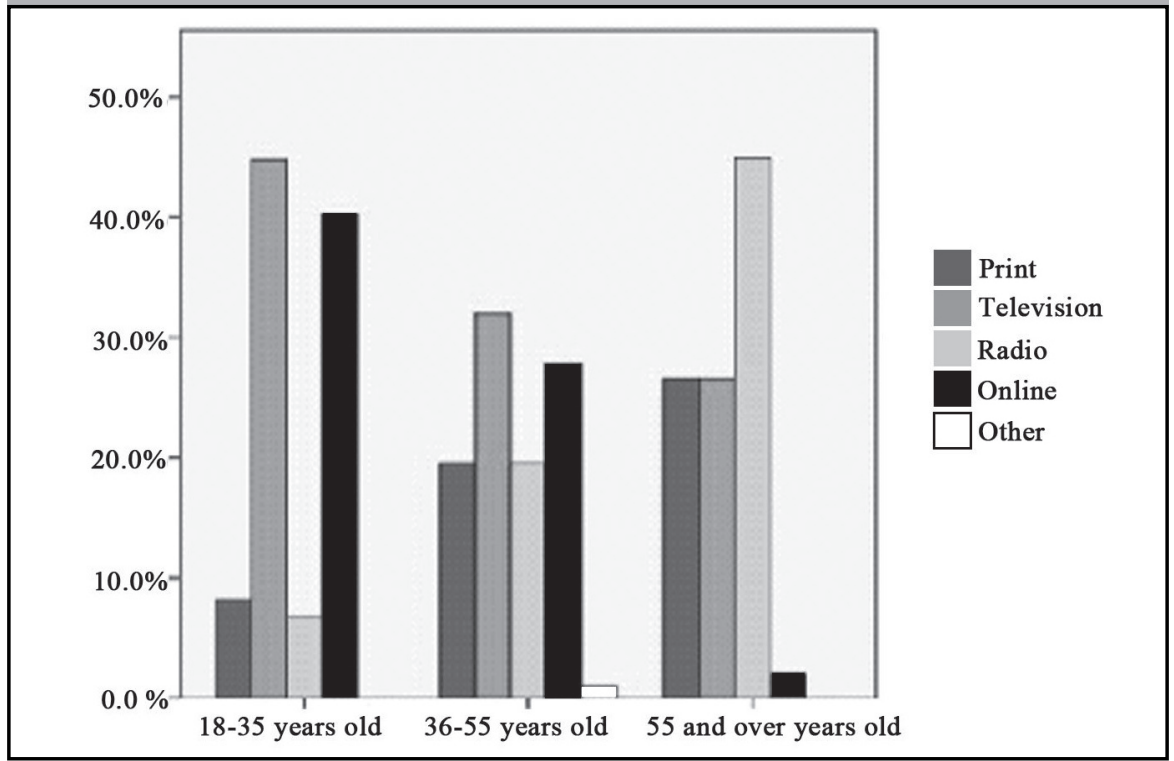

Note: Respondents were asked through which media they received most of their news regarding politics specific to the Ashgrove electorate. The results are expressed as population percentages where the total for each $x$-axis category equals $100 \%(n=280)$

and age, as can be observed in Graph 2. The usage of new media drops dramatically from approximately 40 percent of the 18 to 35 year-old grouping, to a negligible proportion of the 56 and over age group population. A similar inverse relationship between the proficiency of digital tools use and age can be observed in Table 1. These trends support the notion that new media usage is strongly related to the digital literacy of the survey population, and as such new media may be considered to be in its formative stages.

The data presented in Graph 4 relate specifically to new media use. This question was designed to investigate the concerns presented by Richards

\section{Table 1: Age group breakdown}

\begin{tabular}{|l|c|c|c|}
\hline Age bracket & Mean & N & Standard Deviation \\
\hline $18-35$ years old & 8.07 & 134 & 1.607 \\
\hline $36-55$ years old & 5.76 & 97 & 2.065 \\
\hline 56 and over years old & 3.14 & 49 & 1.947 \\
\hline Total & 6.41 & 280 & 2.589 \\
\hline
\end{tabular}

PACIFIC JOURNALISM REVIEW 19 (2) 2013185 


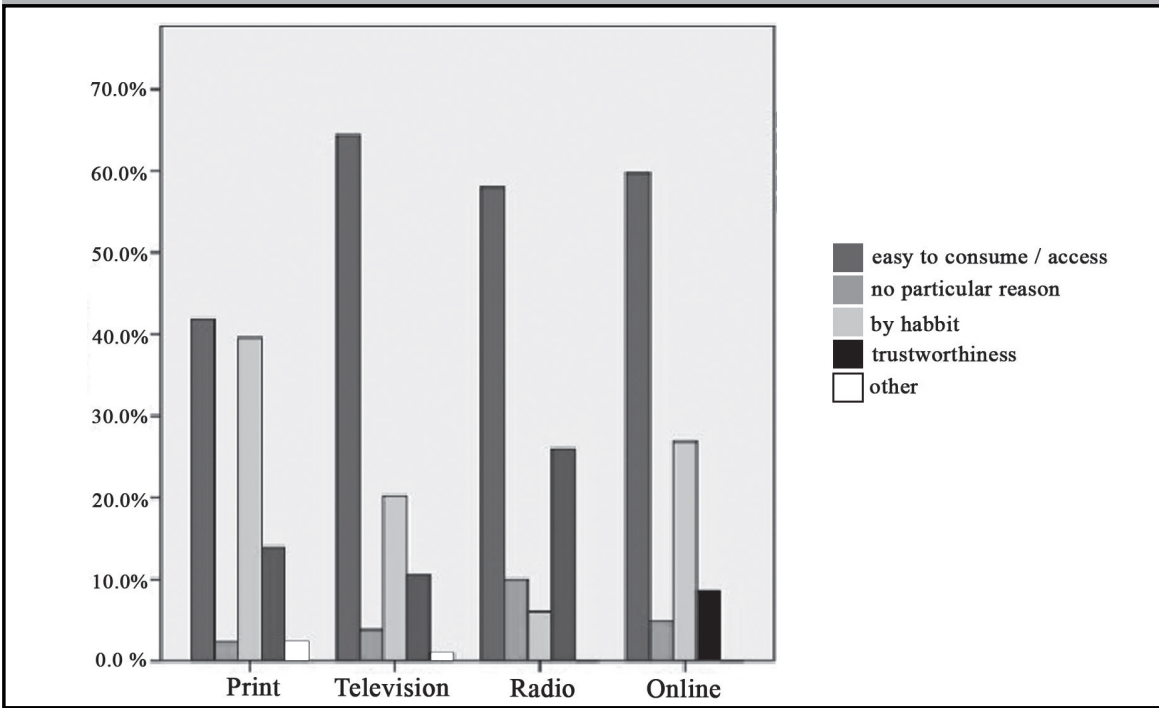

Note: Respondents were asked why they used specific media to reive most of their viewsregarding politics specific to the Ashgrove electorate. The results are expressed as population percentages where the total of each $\mathrm{x}$-axis category equals $100 \%$ $(n=280)$.

(2007), namely that online media enable audiences to absorb news as consumers, rather than follow news more widely as citizens. The data show that the majority of the survey population, who use new media most, use it as a specific search tool rather than as a means to follow news in a broader context. This trend, if seen as choosing from what is known and liked rather than accessing a broad offering, may have a negative influence on notions of an informed citizenry, which is ultimately necessary for a wholly functional democracy. (In an alternative interpretation, new media users might be getting a better quality of information and information use, through having a close engagement in interactive exchanges - although the view of the authors is that the volume of political matter chosen is likely to be too sparse to be of great use).

Concluding, this section has found that the use of new media is an emerging trend for news consumption in the survey population. However, conventional media outlets, such as television, radio and print, still remain the most used avenues. The data also suggest that constituents who use new media are inclined to consume news on specific topics of interest rather than in a broader context-with younger demographics marginalising the need for trustworthiness in this setting.

186 PACIFIC JOURNALISM REVIEW 19 (2) 2013 


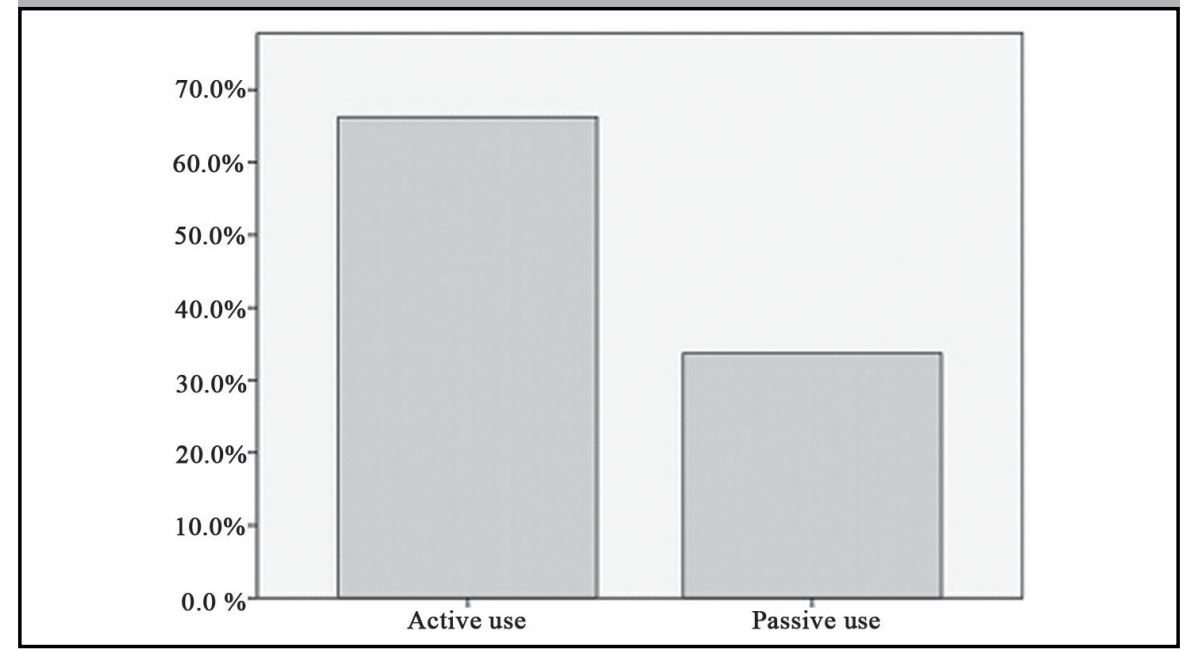

Note: Of the respondents who answered that they received most of their news from online media, a follow up question was asked to determine how they used new media. The results are expressed as population percentages $(n=86)$.

\section{Trends in political knowledge, participation and importance of politics}

The overall importance placed on politics rated significantly low among all age groups, with a total survey population mean of 4.65 out of 10 . The low importance placed on politics is mirrored in the participation rates, with almost 80 percent of the survey population not having participated in any political forums in the past three months (forums are defined as meetings in groups of any size, or online exchanges). These figures prove a precursor for the survey population's awareness rates of the Ashgrove electorate's candidates.

When asked for the names of candidates running for the Ashgrove seat, one quarter of respondents did not know that Kate Jones was the ALP candidate. Moreover, one fifth of respondents did not know what position Campbell Newman aimed to achieve by securing the Ashgrove electorate. This demonstrates that a notable portion of the survey population was not familiar with important information regarding the election. It also suggests a lack of an aggregated social discourse with which to support an actualisation of professional-amateur collaborations, at least to the extent suggested by Beckett (2008) in networked journalism. 


\section{Trends in voting behaviour and influences}

ReachTEL, a data collection and marketing company, surveyed 524 constituents of the Ashgrove electorate in September (2011) using an automated phone polling system. ReachTEL found that Campbell Newman would 'comfortably win his seat on primary votes alone' with 54.8 percent, a prediction reflected in this study's survey, which found 53.2 percent of the primary vote would go to Campbell Newman.

This clear swing in favour of the LNP, in an electorate that the ALP had predominantly held for the last 20 years, suggested there was an aggregated social discourse present, despite relatively low rates of political knowledge, negative views on the importance of politics, and little active political participation. Perhaps relatedly, Graph 5 shows that the media would remain a strong element in political decision-making, and in the overall democratic discourse of the electorate. This study does not extend to examining the characteristics of such media influence or media use, for example whether audience members are using media autonomously for their own purposes, or being led by messages received through mass media. However, for the purposes of this study, it is reasonable to propose that this media presence serves in some capacity to reinforce democratic processes, online and offline, which offers one explanation of its market penetration as shown in Graph 5.

\section{Graph 5: Infiluences on voting intentions}

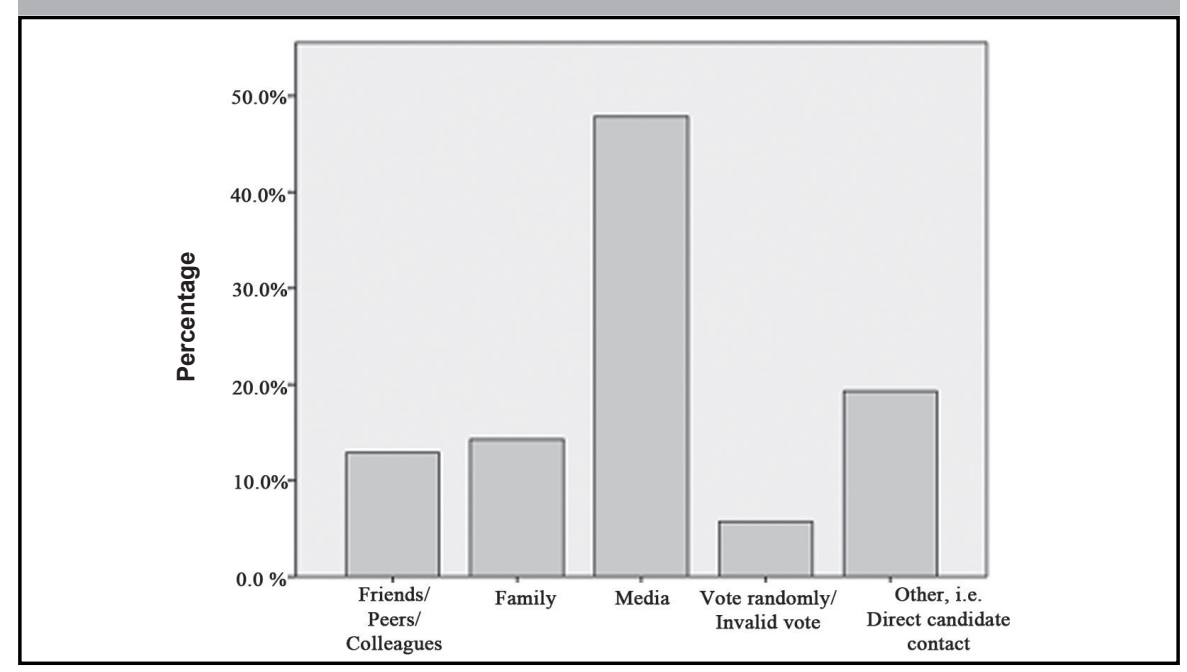

Note: Respondents were asked which of the following factors listed on the $\mathrm{x}$-axis has the strongest influence on their voting intentions for the upcoming elections. The results are expressed as a percentage of the population $(n=280)$.

188 PACIFIC JOURNALISM REVIEW 19 (2) 2013 


\section{Interview analysis}

\section{Ashgrove political landscape}

As a starting point, questions were put to the panel of interviewees about the political landscape of Ashgrove, and how the dynamics of the electorate might influence the election outcome. The panel interviewed unanimously agreed there was a unique complex of dynamics in Ashgrove, with a bearing on what issues would decide the election, and how they would be discussed.

On March 22, 2011, Campbell Newman, then Brisbane Lord Mayor, announced his plans to run for LNP pre-selection for the state seat of Ashgrove, in a bid to unseat Anna Bligh as then Queensland Premier. Kate Jones, the Environment and Resource Management Minister at the time of Newman's announcement, held the seat for Labor with a healthy 7 percent margin, making it on paper one of the hardest seats in Queensland to win for the LNP. This set in motion the events that led to the resignation of the then Opposition Leader John-Paul Langbroek, and his deputy Lawrence Springborg. This cleared the way for Newman to lead the LNP to the 2012 state election, conditional on him securing the Ashgrove electorate. It meant he would be leading the LNP from outside parliament, a situation Prasser described as 'unheard of'.

Prasser, Gleeson, Yuille and Cross would all claim that Newman's ambitions in state politics had put the Ashgrove electorate in the media spotlight, affording him a 'higher media profile', said Cross. However, despite being armed with an impressive recognition rate and résumé as Brisbane Lord Mayor, 'Newman still has to win over the constituents of one of the safest Labor seats,'Yuille said. He suggested also there was an old culture in Ashgrove, settled in the 1930s, which provided cheap, affordable houses for young Catholics who became 'rusted onto Labor for years'. Prasser took this in a different direction, to say that certain dynamics such as socio-economic status factors indicated that Ashgrove could be considered as a Liberal seat. Gleeson, the LNP campaign manager for Ashgrove, agreed to an extent with Prasser's analysis, contending that on a spectrum Ashgrove should be viewed as 'soft to moderate Liberal, or conservative Labor', with local Greens and Labor voters both fairly conservative in outlook. However, Gleeson maintains voting in the electorate will always be influenced by state and federal politics, and as discussed in the next section, this proposition is a key element of political decision-making in Ashgrove 2011. 


\section{Political decision-making}

The respondents unanimously agreed that the driving force behind the swing in voting intentions for Newman, as shown by the survey results in this paper, was state politics, namely dissatisfaction with Anna Bligh as Queensland Premier. Jones suggested constituents did not seem dissatisfied with her representing them, but they were weary of Labor at a state and federal level. She said that a large percentage of people vote for a government, informed by the media, rather than their local representative - a point that again was mirrored in the survey results.

Yuille reinforced Jones' proposition that people were 'sick of Labor' as a brand, over federal issues like bungling of the household insulation rollout, or in Queensland, regarding the asset sell-off or the health payroll fiasco. He proposed that these issues were symbolic of economic concerns that unsettled voters, because 'more people care about money than they do politics'. He proposed that people's financial situations are seen as big restrictions on their hopes and aspirations, and thus cost of living, tax, interest rates, and rent were all big concerns when it came to political decision-making: 'The feel in Ashgrove is that the economy is going backwards, and we have to blame the government, which is Labor'. He concluded that the Ashgrove community might stand to lose much, because people may have borrowed against their houses when times were prosperous, and now it was 'going bad'. Voting for Newman was an act of clutching at the last straws - people thought that he might be able to turn back the economic swing, against the burden of interest payments.

Jones put against this the argument that debt acquired by Brisbane with Campbell Newman as Lord Mayor, and consequential rates rises for residents, was crucial information to be recognised when considering hopes for better economic prospects. Polkowski believed Newman's high media profile could handicap him in this respect, inciting increased scrutiny of his past and future endeavours: 'His intentions are obvious, he wants the seat of Ashgrove because he wants to be premier. Whether or not constituents punish him for this will show come voting day'.

\section{Political participation and communication}

From the perspective of the respondents, the notions of political participation and communication are dependent on there being a certain level of awareness or knowledgeability among the public. Taking the same line of

190 PACIFIC JOURNALISM REVIEW 19 (2) 2013 
argument that Siebert, Peterson \& Schramm (1956) did in a classic text, the respondents viewed the media as having a crucial role in informing the public, and guiding democratic discourse by acting as a fourth estate - a social institution. The survey conducted for this paper affirms this assertion, showing the strongest element in determining voting intentions in the Ashgrove electorate remains the use of media, followed by direct candidate contact.

Manfred Cross, former Labor member for Brisbane, Queensland, said he observed this trend when assisting with political stalls. He suggested the most effective way to influence voters was to physically communicate with them, to 'create the perception that you are available for the people ... because every person who wants to talk to you should have the opportunity'. Polkowski agreed, suggesting the key difference in campaigning between now and 1969, prior to the mass uptake of the internet, was in the personalisation of the process: 'With the uptake of digital communication, the process of political communication became de-personalised, and people became disconnected from the debate ... somewhere along the way people's passion for politics died'.

Cross added the observation that the lack of participation and communication on behalf of the public could be attributed also to a lack of political agenda. In his explanation, it was large issues such as the Vietnam War, conscription and the depression, which got people involved in, and talking about politics. As Yuille continued, these issues do not exist to the same extent; furthermore, there were few strategic policies applicable to Ashgrove due to the pragmatic campaign dynamics: 'Why would Newman provide legislation when people want him in because they're sick of Labor? He's going to sit back and ride the swing into the election, and this is where democracy loses out'.

\section{The online public sphere}

Prasser crystallised the concerns raised by the panel regarding use of online forums in democratic discourse: 'It comes down to the quality of engagement, and people who use online usually don't have a wide enough news habit to fully understand political issues'. He proposed that those who use online media as their main source of news might lack experience of a level of editorial quality in their news habit, which usually comes with professionally assembled packages. He explains, 'It is easy to look up something [online], but as far as consuming broad topics of news goes, which makes quality discussion possible, online for me is a great consumption of time compared to radio, and a lot of youth can't make that comparison'. 
Prasser, Polkowski and Gleeson would assert to varying degrees that young people are 'ill-informed in general', not just when it comes to current affairs and politics. Prasser added the online public sphere was in itself indicative of the generation that mostly inhabits it: 'It's consumer driven [that is why] issues of quality and social agenda will always be of concern in that medium'.

Yuille proposes a positive interpretation of that notion, saying the use of online media, including social media platforms, is a valuable tool to supplement a news habit. He observes that larger news stories attracted more attention online, specifically from older demographic groupings, which would suggest, with adequate levels of digital and media literacy, a quality extension of democracy could exist within the online public sphere.

\section{Discussion}

As outlined previously, Beckett in Supermedia (2008) linked a decline in mainstream publishing to the expansion of online; posited that journalism remained a valued product important to society; proposed various schemes for a professional-amateur solution involving audiences with professionals in producing news; and offered a set of case studies and examples to demonstrate his ideas. It was established in theory that through opening up journalistic practices in this way, an ideal adaptation to changing public-sphere settings in the digital age could occur for journalism and media. The present study set out to provide an insight into the future of new media, judged against such propositions.

The findings of the survey and interview analysis propose that the development of networked journalism, so as to reach critical mass among a population, needs to be built upon current processes of online exchange between those who inhabit this public sphere most. In the present study, the survey population indicated a lack of will to get involved in political discussions online, especially by those equipped to use such media, typically the 18 to 35 -year-old demographic groupings. Inversely, those who placed a high level of importance on politics, and were most willing to engage in informed discussion, were generally ill-equipped to do so online: typically the 55year-old and older demographic groupings, reporting low levels of interest in extending their online usage. Such consensus building as appears to go on, as with the emergence of a clear voting trend in Ashgrove, would appear to be an extension of well-tried forms of community discourse that will process major decisions, of which the older generation would be the main custodians.

192 PACIFIC JOURNALISM REVIEW 19 (2) 2013 
As the survey indicates, these would include interpersonal contact and making use of old or mainstream media.

This poses a significant challenge to the development of networked journalism. However, this study points out that new media is still in its formative stages, and as time progresses, the use of digital tools stands to be taken up by larger, and more extensive, demographic groupings, so the technological barrier which exists today may not be as strong an element in future studies in this field. Currently, the barrier is seen to exclude a significant portion of willing and informed participants from the online public sphere, which has contributed to a lack of social infrastructure, or at least an understanding of its potential and future direction, with which to support networked journalism in the Ashgrove electorate.

Any adaptation or development of networked journalism, or more broadly professional-amateur operations in this context, may benefit from the instigation of structures which focus more on cultivating public engagement through processes familiar to the population, rather than further harvesting it through industry-born approaches. The agency of practitioners, working through both mainstream and new media channels, may provide guidance and cues for participants to be more willing and constructive, contributing to stronger social and democratic discourses, by utilising such tools as the Internet - developing the online public sphere.

In reality, to date economic pressure and a fast-paced newsroom dominate much of the media culture. The aim of this study is to introduce networked journalism as a developing concept, rather than as a knee-jerk cry for an ideal, democratic model or outcome for media in the digital age. This study sees new media use as an emerging trend, but one requiring professional, journalistic skills, both as used by existing media outlets, and, to a significant extent, already deployed among the public, if it is to realise the full democratic potential proposed by practitioners and theorists such as Beckett (2008) and Gillmor (2004). 


\section{References}

Atton, C., \& Hamilton, J. F. (2008). Alternative journalism: London: Sage.

Beckett, C. (2008). Supermedia: Saving journalism so it can save the world. Oxford: Blackwell.

Beckett, C., \& Ball, J. (2012). Wikileaks: News in the networked era. Cambridge: Polity Press.

Biemer, P. P., \& Lyberg, L. (2003). Introduction to survey quality. New Jersey: John Wiley and Sons, Inc.

Blumenthal, S. (2007). Walter Lippmann and American journalism today. Retrieved August 5, 2011, from http://www.opendemocracy.net/article/democracy_power/ america inside/walter_lippman

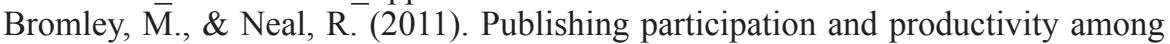
journalist-academics in the era or ERA. [Article]. Australian Journalism Review, 33(1), 55-72.

Federal Communication Commission Oversight Hearing, (2007).

Feeney, A., \& Heit, E. (2007). Inductive reasoning: Experimental, developmental, and computational approaches. New York: Cambridge University Press.

Franklin, B. (2012). The future of journalism. United Kingdom: Routledge.

Gillmor, D. (2004). We the media:Grassroots journalism by the people, for the people. Beijing: O'Reilly.

Habermas, J. (1991). The structural transformation of the public sphere: An inquiry into a category of bourgeois society. Massachusetts: MIT Press.

Habermas, J. (2006). Towards a United States of Europe. Retrieved August 1, 2011, from http://www.signandsight.com/features/676.html

Habermas, J., Lennox, S., \& Lennox, F. (1964). The public sphere: An encyclopedia article. New German Critique (3), 49-55.

Henry, N. (2007). American carnival: Journalism under siege in an age of new media. California: University of California Press.

Hess, S. (1996). International news and foreign correspondents. Washington, D.C.: Brookings Institution.

Jarvis, J. (2006). Networked journalism. Retrieved April 1, 2012, from http://www. buzzmachine.com/2006/07/05/networked-journalism/

Kushin, M. J. (2010). Tweeting the issues in the age of social media? Intermedia agenda setting between the New York Times and Twitter. Unpublished 3421635, Washington State University, United States .

Lippmann, W. (1997). Public opinion. New Jersey: Transaction Publishers.

Mason, J. (2002). Qualitative researching. London: Sage Publications.

McChesney, R. W., \& Pickard, V. (2011). Will the last reporter please turn out the lights: The collapse of journalism and what can be done to fix it. New York City: The New Press.

Meikle, G., \& Redden, G. (2011). News online: Transformations and continuities. New York: Palgrave.

Moser, C. A., \& Kalton, G. (1971). Survey methods in social investigation. New Hampshire: Heinemann Educational.

194 PACIFIC JOURNALISM REVIEW 19 (2) 2013 
Overholser, G. (2006). On behalf of journalism: A manifesto for change. Annenberg Foundation Trust at Sunnylands: United States of America.

Pavlik, J. V. (2001). Journalism and new media. New York: Columbia University Press.

ReachTEL. (2011). Ashgrove polling. Retrieved October 2, 2011, from http://www. reachtel.com.au/blog/ashgrove-electorate-campbell-newman-kate-jones

Richards, E. (2007). Media literacy. Retrieved August 1, 2011, from http://www. ofcom.org.uk/advice/media_literacy/

Schudson, M. (2002). The news media and political institutions. Annual Review of Political Science, 5(1), 249-269.

Siebert, F. S., Peterson, T., \& Schramm, W. (1956). Four theories of the press: The authoritarian, libertarian, social responsibility, and Soviet communist concepts of what the press should be and do. Illinois: University of Illinois Press.

Sonnenberg, L. (2009). New media technologies and the transition to personal public spheres. Unpublished 1469135, State University of New York at Buffalo, United States.

Tewksbury, D. (2005). The seeds of audience fragmentation: Specialization in the use of online news sites. Journal of Broadcasting \& Electronic Media, 49(3), 332-348.

Viall, E. K. (2009). Hyper-local citizen journalism sites and traditional media sites: Similarities and contrasts in theme, objectivity, and watchdog function. Unpublished 3390311, Indiana University, United States.

Yin, R. K. (1984). Case study research: Design and methods. London: Sage Publications.

Steve Fox is an Endeavour Australia Cheung Kong research fellow and PhD student at the Queensland University of Technology. He has published scholarly articles on the topics of social capital in new media ecologies, and maintains a research focus in the Asia-Pacific region, specifically public policy in South Korea.

s1.fox@qut.edu.au

Dr Lee Duffield is a senior lecturer in journalism at the Queensland University of Technology, Brisbane, and postgraduate coordinator there for Journalism Media and Communication. He is a staff elected member of the governing Council, and a member of the University Academic Board.

I.duffield@qut.edu.au

PACIFIC JOURNALISM REVIEW 19 (2) 2013195 